ISSN 25980580

Bioscientia Medicina Volume 3, Issue 4, Page No: 21-28

Available online : www.bioscmed.com

Bio Sc Med 3(4) :21-28

\title{
Effect of Intravenous Vitamin C on Urine Neutrophil Gelatinase-Associated Lipocalin Among Septic Patients: Randomized Controlled Trial
}

\author{
Peni Yulia Nastiti ${ }^{1 *}$, Adhrie Sugiarto ${ }^{2}$, Amir S Madjid ${ }^{2}$
}

\begin{abstract}
${ }^{1}$ Trainee of Intensive Care Program, Department of Anesthesiology and Intensive Care, Universitas Indonesia
${ }^{2}$ Staff Lecturer, Department of Anesthesiology and Intensive Care, Universitas Indonesia, Cipto Mangunkusumo Hospital, Jakarta, Indonesia
\end{abstract}

*Corresponding Author E-mail:yulia.peni@ymail.com

Received : August $17^{\text {th }} 2019$

Accepted : October $28^{\text {th }} 2019$

\begin{abstract}
Background

The role of vitamin $\mathrm{C}$ to decrease organ dysfunction in sepsis was still controversial. This study aimed to explore the effect of intravenous (IV) vitamin C on urine NGAL (uNGAL) levels among septic patients in ICU.

Methods

This study was a randomized clinical trial held in Cipto Mangunkusumo Hospital from April to July 2019 with consecutive sampling method. Patients aged > 18 years with sepsis based on the criteria of sepsis-3 who were admitted to the ICU were included in this study. Exclusion criteria were those with chronic kidney problems, with kidney stones, undergo renal replacement therapy in the ICU. All subjects were divided into: Group A was treated with combination of vitamin $\mathrm{C}$ and thiamine while Group B was given thiamine only. The uNGAL level was measured at baseline, 24, 48 and $72 \mathrm{~h}$ after treatment. Anova for repeated measurement using General Linear Model for Repeated Measurement was used with level of significant at p-value $<0.05$.

Results

Total of 33 subjects were included. In Group A we found uNGAL (ng/ mL) were 74.5 (13.3-102.9), 77.3 (15.298.4), 67.2 (22.6-100.6), 77.2 (17.0-100.5) for baseline, 24 h, 48 h, and 72 h respectively. While in Group B uNGAL were 57.7 (11.5-94.5), 57.1 (6.4-97.7), 53.7 (13.3-99.6), 47.6 (4.5-100.9). No significant difference in terms of uNGAL between two groups at each hour was found.
\end{abstract}

Conclusions

This study showed that intravenous vitamin C administration had no effect on uNGAL among septic patients. Need more study to investigate approaches to improve kidney and inflammatory biomarker among septic patients.

Keywords: sepsis, intravenous vitamin $C$, urine $N G A L$

\section{Introduction}

Sepsis is caused by dysregulated host response to infection which leads to lifethreatening organ dysfunction.[1] Mortality due to sepsis in critically ill patients is around 3050\%.[2] Fifty-one percent of sepsis patients develop acute kidney injury (AKI), which is very 
ISSN 25980580

serious complication in intensive care unit (ICU) that morbidity, mortality and treatment costs would increase.[3] Currently, diagnostic criteria of AKI was based on Acute Kidney Injury Network (AKIN) classification.

Oxidation contributes to increased highly reactive species free radicals production. This would cause further chain reactions which leads to cell damage, including apoptosis in kidney tubule cells.[4,5] It is possible that antioxidant supplementation may provide potential advantages due to the role of oxidative stress in the pathogenesis of sepsis. The most studied antioxidant molecule is vitamin C. Studies showed intravenous vitamin C was effective at reducing mortality and organ injury by using pleiotropic mechanisms. High-dose ascorbate administration can counteract the oxidative phosphorylation uncoupling leading to reactive oxygen species (ROS) reduction.[4,6]

Neutrophil gelatinase-associated lipocalin (NGAL) is the most widely published biomarker. Elevated urine NGAL is a signal of early kidney function decline which is reflected by increased creatinine.[7]

However, current results of past studies involving antioxidant supplementation, including vitamin $\mathrm{C}$, were highly varied. Study by Heyland et al showed administration of vitamin C (1500 mg/ day) combined with other antioxidants failed to improve survival in critically ill adults. Contradictory, Marik et al showed extreme mortality reduction in septic patients receiving the vitamin "cocktail" and reduction of renal replacement therapy event between treatment group and placebo $(10 \%$ vs $33 \%, p=0,02)$. [8,9] Hence, we would evaluate role of vitamin $\mathrm{C}$ in critical patients by using randomized clinical trial. This study aimed to explore the effect of intravenous vitamin $\mathrm{C}$ on uNGAL levels among septic patients in ICU.

\section{Methods}

This study was a randomized clinical trial held in Cipto Mangunkusumo Hospital from April to July 2019 with consecutive sampling method. Patients aged > 18 years with sepsis diagnosis based on sepsis- 3 criteria who were admitted to the ICU and who were in between 6 $\mathrm{h}$ and $24 \mathrm{~h}$ post resuscitation after sepsis diagnosis in ICU were included in this study. Meanwhile, exclusion criteria were patients with chronic kidney problems on hemodialysis, , kidney stones or kidney problem within the last 3 months. The drop out criteria were patients

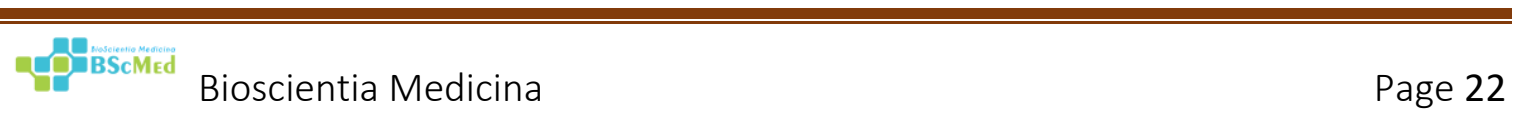


ISSN 25980580

underwent renal replacement therapy in the ICU within $72 \mathrm{~h}$ observation and who were given corticosteroid within $72 \mathrm{~h}$. A written consent was obtained from all study participants.

Subjects were determinated by simple randomization using random number table and divided into two groups. Patients in Group A was administered IV vitamin C 1,5 grams per 6 hours and thiamine $200 \mathrm{mg}$ per 12 hours. In Group B was given thiamine only. The treatment was given on first day until $3^{\text {rd }}$ day in ICU. Baseline demographic data was recorded on the first day. Sequential Organ Failure Assessment (SOFA) score was recorded at baseline, 24, 48 and $72 \mathrm{~h}$ after treatment. Daily measurements of uNGAL was started as baseline level and continued at 24, 48 and $72 \mathrm{~h}$ after treatment. The enzyme-linked immunosorbent assay kits were utilized for measuring urine NGAL (Quantikine® ELISA R\&D systems, Minneapolis) and the level was defined as their total consentrations in urine $(\mathrm{ng} / \mathrm{mL})$. The outcome of study was the change in uNGAL levels over the 72-hours. SPSS software version 23.0 (SPSS Inc, Chicago, III, USA) was used to perform statistical analysis. For continuous variables, results were displayed as mean values \pm standard deviations for normally distributed data and median (minimum-maximum) for not normally distributed data. For categorical data, result used frequency and percentages. Comparison between both groups was analysed by using Mann Whitney test for numerical data and Fisher test for categorical data. Anova for repeated measurement using General Linear Model for Repeated Measurement was used for serial measurement analysis. Wilcoxon pair comparison test was done for analyzing before and after treatment effect. Level of significant was determined at $\mathrm{p}$-value $<0.05$.

\section{Results}

Table 1. Baseline demographic data of Group A and B

\begin{tabular}{llcc}
\hline & & $\begin{array}{l}\text { Group A } \\
(\mathrm{n}=18)\end{array}$ & $\begin{array}{l}\text { Group B } \\
(\mathrm{n}=15)\end{array}$ \\
\hline Age, mean \pm SD,y & & $45.39 \pm 15.06$ & $46 \pm 16.6$ \\
Sex, male, $(\%)$ & $10(55.6)$ & $7(46.7)$ \\
& & & \\
Diagnosis, (\%) & Sepsis & $7(38.9)$ & $6(40)$ \\
& Septic shock & $11(61.1)$ & $9(60)$ \\
Comorbidities, $(\%)$ & No & $7(38.9)$ & $4(26.7)$
\end{tabular}




\begin{tabular}{|c|c|c|c|}
\hline \multirow{7}{*}{ Source of sepsis, $(\%)$} & & & ISSN 2598 C \\
\hline & Abdominal & $3(16.7)$ & $4(26.7)$ \\
\hline & Pulmonary & $14(77.8)$ & $10(66.7)$ \\
\hline & Soft tissue & $1(5.6)$ & $1(6.7)$ \\
\hline & Medical & $9(50)$ & $10(66.7)$ \\
\hline & Surgical & $4(22.2)$ & $4(26.7)$ \\
\hline & $\begin{array}{l}\text { Medical and } \\
\text { surgical }\end{array}$ & $5(27.8)$ & $1(6.7)$ \\
\hline \multirow{3}{*}{ Type of surgery, $(\%)$} & Abdominal & $5(27.8)$ & $4(26.7)$ \\
\hline & Neurosurgery & $2(11.1)$ & $0(0)$ \\
\hline & other & $2(11.1)$ & $1(6.7)$ \\
\hline $\begin{array}{l}\text { Mechanical ventilation } \\
\text { (yes), }(\%)\end{array}$ & & $18(100)$ & $14(93.3)$ \\
\hline \multirow[t]{3}{*}{$\mathrm{P} / \mathrm{F}$ ratio, $(\%)$} & $>300$ & $10(55.6)$ & $5(33.3)$ \\
\hline & $200-300$ & $5(27.8)$ & $6(40)$ \\
\hline & $<200$ & $3(16.7)$ & $3(20)$ \\
\hline Vasopressor (no), (\%) & & $6(33)$ & $3(20)$ \\
\hline AKI (yes) ${ }^{*},(\%)$ & & 0 & 0 \\
\hline $\begin{array}{l}\text { SOFA score baseline, } \\
\text { mean } \pm S D\end{array}$ & & $7.56 \pm 2.87$ & $9.07 \pm 2.34$ \\
\hline $\begin{array}{l}\text { uNGAL baseline, } \\
\text { mean } \pm \text { SD, ng/mL }\end{array}$ & & $66.06 \pm 30.25$ & $55.78 \pm 31.12$ \\
\hline
\end{tabular}

Forty patients were included in this study, 7 patients were dropped out because they passed away before $72 \mathrm{~h}$ observation. Baseline demographic data of two groups were presented in table 1 . This study did not find any significant differences between two groups regarding these characteristics.

There were no significant differences in UNGAL between the two groups at each hour respectively (table 2). There were also no significant changes in uNGAL level in before and after treatment analysis either in Group A $(\mathrm{p}=0.811)$ or in Group B $(\mathrm{p}=0.865)$ (figure 1). 


\section{ISSN 25980580}

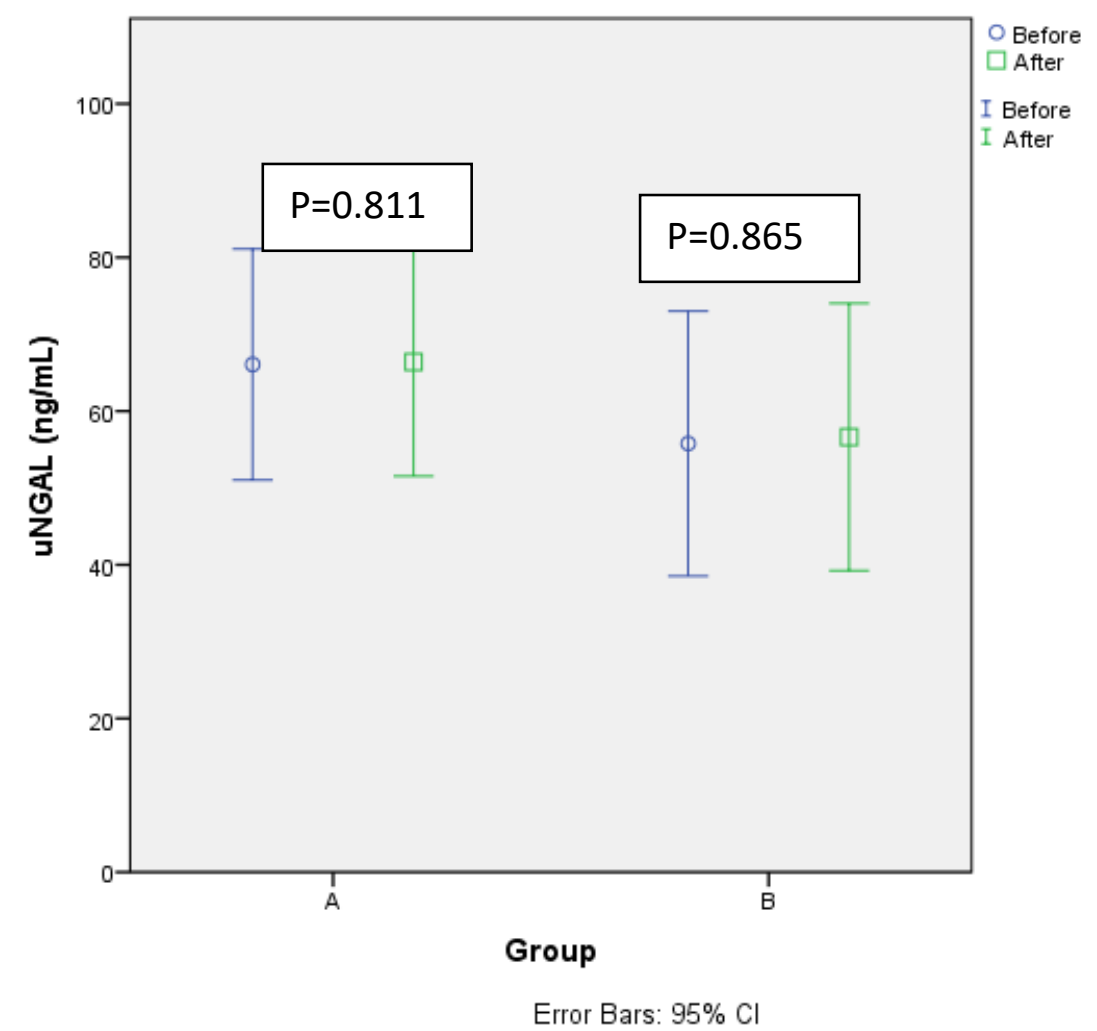

Figure 1 : Changes in uNGAL at before and after treatment in Group A and Group B

Table 2. uNGAL levels in the two study groups

\begin{tabular}{clll}
\hline Characteristic & \multicolumn{1}{c}{$\begin{array}{c}\text { Group A } \\
\text { Median (IQR) }\end{array}$} & $\begin{array}{c}\text { Group B } \\
\text { Median (IQR) }\end{array}$ & p-value \\
\hline uNGAL (ng/mL) & & & \\
Baseline & $74.5(13.3-102.9)$ & $57.7(11.5-94.5)$ & 0.345 \\
24-hours & $77.3(15.2-98.4)$ & $57.1(6.4-97.7)$ & 0.283 \\
48-hours & $67.2(22.6-100.6)$ & $53.7(13.3-99.6)$ & 0.730 \\
72-hours & $77.2(17.0-100.5)$ & $47.6(4.5-100.9)$ & 0.368 \\
\hline
\end{tabular}

\section{Discussion}




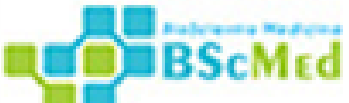

ISSN 25980580

Based on AKIN classification, all subjects in this study were not in AKI condition at ICU admission. However, this would be different if using NGAL parameter. A research evaluating plasma NGAL for early AKI diagnosis in a heterogenous adult patients concluded nearly $30 \%$ had AKI within the first day of admission. Additionally, there were $44 \%$ of patients had AKI during their ICU admission.[3,10] From uNGAL data, there was very wide range of levels was found in general ICU population. Endre et al found similar results in their study.[11] uNGAL could be measured in critically ill patients within the first day of admission. However, this may not indicate the first day from the onset of the disease itself. In the ICU, "multiple injuries" of varying severity might impact the kidney in the process; this was different from the "single injury" model found in most patients underwent surgery.[12] Additionally, NGAL is also served as a marker of bacterial infection and systemic inflammation which was released by neutrophil activation.[7] However, systemic stress could increase uNGAL excretion in the absence of AKI which generated substantial extrarenal NGAL; similar findings may also found from both chronic and acute renal illness.[13] Hence, for future reference, combinations of biomarkers, including liver fatty acid-binding protein (L-FABP) and cystatin-C, could allow AKI diagnosis among septic patients.[11]

This study is currently the first trial that explores the effect of IV vitamin C on uNGAL in septic patients. However, there was no significant changes in UNGAL level in before and after treatment analysis in two groups. The reason might be high-dose intravenous vitamin $\mathrm{C}$ should be limited to only early phase of sepsis conditions. This is because intracellular signalling is initiated by low level of ROS.[14] However, in this study majority of subjects came from tertiary referral hospital with complex medical problems; hence, the subjects were already in long-term release of ROS. Further studies should exclude patients with terminal end stage disease, including those who are less likely to survive, patients with sepsis condition more than 24 hours before admission or those who were already treated in or referred from other institutition.

Abiles et al studied the association between oxidative stress, vitamin intakes, and SOFA scores among critically ill patients. This study found worsened oxidative stress among patients with antioxidant vitamin intakes below recommended dietary allowance (RDA). Hence, dose adjustment should be personalised based on the level of each patient's antioxidant level. Additionally, antioxidant vitamins intakes should be monitored carefully to personalise the 
ISSN 25980580

dose in accordance with the RDA.[15] However, there were variable responses toward vitamin $\mathrm{C}$ administration among critically ill patients.[16] For future reference, there are several issues remain unsolved including pharmacokinetics of vitamin $\mathrm{C}$ and other antioxidants supplementation.

\section{Conclusion}

This study showed that intravenous vitamin $\mathrm{C}$ administration had no effect on uNGAL among septic patients. Further study was required to investigate the role of vitamin as antioxidant in critically ill patients.

\section{Acknowledgements}

The authors would like to send gratitude for the staff in Cipto Mangunkusumo Hospital, Department of Anesthesiology and Intensive Care, Universitas Indonesia, for their support of this research project, which was a part of thesis for intensive care consultant.

\section{References}

[1] Singer M, Deutschman CS, Seymour C, Shankar-Hari M, Annane D, Bauer M, et al. The third international consensus definitions for sepsis and septic shock (sepsis-3). JAMA 2016;315:801-10.

[2] Carr AC, Shaw GM, Fowler AA, Natarajan R. Ascorbate-dependent vasopressor synthesis: A rationale for vitamin $\mathrm{C}$ administration in severe sepsis and septic shock? Crit Care 2015;19:418.

[3] Bagshaw SM, George C, Bellomo R. Early acute kidney injury and sepsis: a multicentre evaluation. Crit Care 2008;12:R47.

[4] Forni LG. Metabolic resuscitation in sepsis: could antioxidants be the answer? Signa Vitae 2017;13:16-9.

[5] Bellomo R, Kellum JA, Ronco C, Wald R, Martensson J, Maiden M, et al. Acute kidney injury in sepsis. Intensive Care Med 2017;43:816-28.

[6] Natarajan R, Fisher BJ, Syed AA, Fowler AA. Impact of intravenous ascorbic acid on novel biomarkers in patients with severe sepsis. J Pulm Respir Med 2014;4:214.

[7] Martensson J, Bell M, Oldner A, Xu S, Venge P, Martling C-R. Neutrophil gelatinase-

$\begin{array}{lr}\text { Bioscientia Medicina } & \text { Page } 27\end{array}$


associated lipocalin in adult septic patients with and without acute kidney injury. Intensive Care Med 2010;36:1333-40.

[8] Heyland D, Muscedere J, Wischmeyer PE, Cook D, Jones G, Albert M, et al. A randomized trial of glutamine and antioxidants in critically Ill patients. N Engl J Med 2013;368:1489-97.

[9] Marik PE, Khangoora V, Rivera R, Hooper MH, Catravas J. Hydrocortisone, vitamin C, and thiamine for the treatment of severe sepsis and septic shock: a retrospective beforeafter study. Chest 2017;151:1229-38.

[10] Cruz DN, De Cal M, Garzotto F, Perazella MA, Lentini P, Corradi V, et al. Plasma neutrophil gelatinase-associated lipocalin is an early biomarker for acute kidney injury in an adult ICU population. Intensive Care Med 2010;36:444-51.

[11] Endre ZH, Kellum JA, Di Somma S, Doi K, Goldstein SL, Koyner JL, et al. Differential diagnosis of AKI in clinical practice by functional and damage biomarkers: workgroup statements from the tenth acute dialysis quality initiative consensus conference. Contrib Nephrol 2013;182:30-44.

[12] Fisher BJ, Kraskauskas D, Martin EJ, Farkas D, Puri P, Massey HD, et al. Attenuation of sepsis-induced organ injury in mice by vitamin C. JPEN J Parenter Enter Nutr 2014;38:825-39.

[13] Urbschat A, Obermuller N, Haferkamp A. Biomarkers of kidney injury. Biomarkers 2011;16:S22-30.

[14] Oudemans-van Straaten HM, Elbers PWG, Spoelstra-de Man AME. How to give vitamin C a cautious but fair chance in severe sepsis. Chest 2017;151:1199-200.

[15] Abilés J, de la Cruz AP, Castaño J, Rodríguez-Elvira M, Aguayo E, Moreno-Torres R, et al. Oxidative stress is increased in critically ill patients according to antioxidant vitamins intake, independent of severity: A cohort study. Crit Care 2006;10:1-9.

[16] Galley HF, Howdle PD, Walker BE, Webster NR. The effects of intravenous antioxidants in patients with septic shock. Free Rad Biol Med 1997;23:768-74. 